\title{
Adult T-cell Leukemia
}

\author{
Kiyoshi TAKatsuki
}

\begin{abstract}
Adult T-cell leukemia (ATL) was first reported in Japan, where it has a high incidence in the southwestern region. The retrovirus, human T-lymphotropic virus type I (HTLV-I), is the causative agent of ATL. In ATL-endemic areas, the rate of HTLV-I carriers is high. A definite diagnosis of ATL is based on the presence of HTLV-I proviral DNA in the tumor cell DNA. ATL cells originate from the CD4 subset of peripheral T cells. ATL shows diverse clinical features but can be divided into four subtypes: acute, chronic, smoldering, and lymphoma type. Chemotherapy is not effective; the acute and lymphoma types have a poor prognosis. Familial occurrence of ATL is common. HTLV-I infection is caused by transmission of live infected lymphocytes from mother to child, from man to woman, or by blood transfusion. Infection with HTLV-I can lead to other diseases, including HTLV-I-associated myelopathy/tropical spastic paraparesis and HTLV-I uveitis.
\end{abstract}

(Internal Medicine 34: 947-952 1995)

Key words: lymphoma, retrovirus, HTLV-I, hypercalcemia

\section{Introduction}

Adult T-cell leukemia (ATL) was first identified in Japan and internationally recognized in $1977(1,2)$. The causative agent human T-lymphotropic virus (HTLV), was first isolated by Gallo's group from cultured cells from one patient with an aggressive variant of mycosis fungoides and one with Sezary syndrome (3). Although both patients were thought to have cutaneous T-cell lymphoma, they had several unusual features that suggest the disorder now called ATL. In Japan, Miyoshi's group established the first cell line MT-1 from a patient with ATL, by co-culturing ATL cells with umbilical cord blood lymphocytes (4). Hinuma and colleagues showed that ATL patients have antibodies against presumed viral antigens (ATLassociated antigens) on MT-1 cells (5) and subsequently isolated and characterized a retrovirus that they named ATLV (6). Since HTLV and ATLV are identical (7), the term HTLV$\mathrm{I}$ is now used.

Immediately after the discovery of ATL and HTLV-I, the acquired immune deficiency syndrome (AIDS) began to be recognized, and a retrovirus, the human immunodeficiency virus (HIV), was also found to be a causative agent in this disease. The advances made in the worldwide study of AIDS owe much to the knowledge gained about the relationship between ATL and HTLV-I. For example, almost identical methods for isolation of HTLV-I were used for the isolation of HIV.

\section{ATL and HTLV-I}

The etiologic association of HTLV-I is based on the following observations: 1) The areas of high incidence of ATL correspond closely with those of high prevalence of HTLV-I infection as extensively studied in Japan. 2) HTLV-I immortalizes human CD4 T cells in vitro. 3) Monoclonal integration of HTLV-I proviral DNA has been demonstrated in ATL neoplastic cells. 4) All individuals with ATL have antibodies against HTLV-I.

HTLV-I is therefore the first retrovirus to be associated directly with human malignancy. Molecular cloning of HTLVI showed that the proviral DNA is flanked by 5' and 3' long terminal repeats (LTRs) integrated into host cellular DNA (8). The complete sequences of HTLV-I gives open reading frames for $g a g, p o l$ and $e n v$ genes in the usual order. A unique feature of HTLV-I is the presence of a long sequence, $\mathrm{pX}$ region, between env gene and the 3' LTR. This region codes for at least two genes, tax and rex. No homology exists between tax and any known oncogene. The tax gene product is responsible for enhancement of transcription of viral and cellular genes (9-11). For example, transfection of the tax gene to T-cell lines, but not to B cells, induces interleukin 2 (IL-2) receptor gene expression. The tax protein has been thought to play a critical role in leukemogenesis.

\section{Epidemiology of ATL and HTLV-I infection}

Both HTLV-I and ATL have been shown to be endemic in some regions of the world, especially in southwest Japan (12), 
the Caribbean islands, the countries surrounding the Caribbean basin, and parts of Central Africa (13-15). An unexpected seroprevalence of HTLV-I was found in Melanesia, especially in Papua New Guinea (16). Seropositivity was also detected in Australian Aborigines and in some areas of the Solomon Islands (17). Antibodies against HTLV-I have been found in over one million individuals (18), and more than 600 cases of ATL have been diagnosed each year in Japan alone. The cumulative (life span of 70 years) incidence of ATL among HTLV-I carriers in Japan is estimated at 2.5\% (3-5\% in males and $1-2 \%$ in females) if competing risks for other diseases are disregarded (19).

Seroepidemiologic studies in Japan have indicated that the incidence of HTLV-I infection varies among cities within the endemic region (20). This clustering is thought to be due to the limited transmission of virus between socially isolated populations. In endemic areas of Japan, anti-HTLV-I antibodies were found in the sera of 6 to 37 percent of healthy adults over 40 years of age. The pattern of HTLV-I transmission is through one of three different modes. HTLV-I infected mothers can transmit the virus to newborns mainly via breast milk. HTLV-I antigens in mononuclear cells were detected from breast milk of HTLV-I positive mothers after delivery (21). Primary HTLV-I infection of infants by their mothers has been reported in follow-up studies. Children born to carrier mothers were examined with respect to feeding procedures. No evidence of infection was detected in 10 never-breast-fed children. However, 14 (38\%) of 43 breast-fed children were positive for anti-HTLV-I antibodies in their sera (22). These findings suggest that the major maternal transmission route of HTLV-I is via breast milk. If HTLV-I can be transmitted mainly via breast milk, most infants of HTLV-I carrier mothers should not become infected if they are fed only by HTLV-I-free milk. The intervention of breast-feeding showed that the frequency of seropositive children born to carrier mothers by formula feeding decreased to about $3 \%$ compared with that (about 20\%) of breast-fed children (22). This confirmed that vertical transmission was caused mainly by breast milk, but other routes of transmission existed. The virus also can be transmitted from male to female by sexual intercourse (23), and through blood transfusion (24).

\section{Clinical features of ATL}

We studied 187 patients with ATL. There were 113 males and 74 females (1.5:1), whose age at the onset ranged from 27 to 82 years, with a median age of 55 years. The predominant physical findings were peripheral lymph node enlargement (72 percent), hepatomegaly (47 percent), splenomegaly ( 25 percent), and skin lesions (53 percent). Various skin lesions, such as papules, erythema, and nodules being frequently observed in ATL patients. ATL cells densely infiltrate the dermis and epidermis, forming Pautrier's microabscesses in the epidermis. Hypercalcemia (25) was frequently (28 percent) associated with ATL. Other findings at onset were abdominal pain, diarrhea, pleural effusion, ascites, cough, sputum, and an abnormal shadow on chest X-ray films.
The white blood cell (WBC) count ranged from normal to $500 \times 10^{9} / l$. Leukemic cells resembled Sezary cells, having indented or lobulated nuclei. The typical surface phenotype of ATL cells characterized by monoclonal antibodies was CD3+, CD4+, CD8-, and CD25+. Anemia and thrombocytopenia were rare. Eosinophilia was frequently observed in ATL patients as well as other T-cell malignancies (26).

Serum calcium and lactate dehydrogenase levels reflect the extent of disease and are useful for monitoring the remaining tumor or disease activity. Hyperbilirubinemia, observed when ATL cells infiltrate the liver, indicates a poor prognosis. Serum b2-microglobulin is also elevated in ATL patients also being correlated with disease activity (27). ATL cells were known to express interleukin 2 (IL-2) receptor alpha chain on their surfaces and secrete its soluble forms. Levels of soluble IL-2 receptors as well as levels of serum b2-microglobulin are elevated in the sera of patients with ATL, the levels of soluble IL-2 receptor being correlated with the tumor mass and clinical course $(28,29)$.

Familial occurrences of ATL were reported. Three sisters, ranging in age from 56 to 59 years, who developed lymphomatype ATL during a 19-month period have been reported (30).

\section{Classification of ATL}

ATL patients can be classified into four clinical subtypes according to the clinical features: acute, chronic, smoldering, and lymphoma type (31).

Shimoyama and members of the Lymphoma Study Group (LSG) (1984-1987) proposed the following diagnostic criteria for classifying ATL (32):

1) Smoldering type: $5 \%$ or more abnormal lymphocytes of $\mathrm{T}$ cell nature in the peripheral blood; normal lymphocyte level $\left(<4 \times 10^{9} / l\right)$; no hypercalcemia; LDH value of up to 1.5 -fold the normal upper limit; no lymphadenopathy; no involvement of liver, spleen, central nervous system, bone, or gastrointestinal tract; and neither ascites nor pleural effusion. Skin and pulmonary lesion(s) may be present. In patients with less than 5\% abnormal $\mathrm{T}$ lymphocytes in the peripheral blood, at least one histologically-proven skin or pulmonary lesion should be present.

2) Chronic type: absolute lymphocytosis of more than $3.5 \times 10^{9} / l$; LDH value up to twice the normal upper limit; no hypercalcemia; no involvement of central nervous system, bone, or gastrointestinal tract; and neither ascites nor pleural effusion. There may be histologically-proven lymphadenopathy with or without extranodal lesions and there may be involvement of liver, spleen, skin, and lung, and 5\% or more abnormal lymphocytes.

3) Lymphoma type: no lymphocytosis, $1 \%$ or less abnormal lymphocytes; histologically-proven lymphadenopathy with or without extranodal lesions.

4) Acute type: the most common form of presentation, highly aggressive malignancy that shows lymphadenopathy, hepatosplenomegaly, and skin lesions, but does not meet the criteria of the other types.

The survival time in acute and lymphoma-type ATL ranged from two weeks to more than one year. The causes of death were 
pulmonary complications including Pneumocytis carinii pneumonia (33), hypercalcemia, Cryptococcus meningitis, disseminated herpes zoster, and disseminated intravascular coagulopathies.

These features, as well as the clinical course, ATL subtype, frequencies of hypercalcemia and opportunistic infections, cell morphology, phenotypic profile, and response to treatment appear to be the same for ATL in Japanese, Caribbean, African patients $(13,34,35)$. The only difference is age of onset: the average age is lower for the Caribbean and African than for Japanese ATL patients (43 [19-62] vs 58 [24-85] years).

\section{ATL cells}

Numerous abnormal lymphocytes, which vary considerably in size and cytoplasmic basophilia, are seen in acute ATL. Most of the cells characteristically exhibit lobular division of their nuclei; some are bi- or multifoliate and are separated by deep indentation. Cells with such a nuclear configuration are known as 'flower cells'.

Characterization of ATL cells by monoclonal antibodies reveals that most ATL cells are positive for CD3 and CD4 antigens and are negative for CD8 and CD1 antigens, suggesting that they are derived from mature helper $\mathrm{T}$ cells. In addition, ATL cells have been shown to express activated T-cell markers such as IL-2 receptor and HLA-DR antigen on their surfaces (36). Both activated T-cell markers are infrequently observed on CD4+ chronic lymphocytic leukemic (CLL) cells or Sezary cells, which do not carry proviral DNA of HTLV-I. The mechanism of surface expression of these activated T-cell markers is not clear. It might be that the tax gene of HTLV-I is responsible for expression of these antigens.

Involvement of CD3 and T-cell receptor complexes for proliferation of ATL cells should also be considered, since expression of both of these antigens is decreased in fresh ATL cells (37). Progress of T-cell immunobiology also has provided insights to analyze proliferation of ATL cells. The tax gene could activate the transcription of IL-2 and IL-2 receptor alpha chain gene in vitro, and also ATL cells were well known to express IL-2 receptor alpha chains on their surfaces. These findings have been suggested as one of the mechanisms for involvement of IL-2 and/or its receptors in the uncontrolled proliferation of ATL cells, although the mechanisms of leukemogenesis could not be explained solely by IL-2/IL-2 receptor systems (38-40). Autocrine proliferation of ATL cells by IL- 2 has been found in rare cases (41), although IL-2 did not support proliferation of ATL cells from most of the cases despite abundant expression of the IL-2 receptor gene.

Specific chromosomal abnormalities of ATL cells were not found in ATL. Karyotype analyses of 107 patients with ATL revealed various chromosomal abnormalities as follows (4244): 1) Trisomies of chromosome 3 (21\%), 7 (10\%) and 21 (9\%), monosomy of $X$ chromosome (38\%) in females, and loss of a Y chromosome (17\%) in males were frequent numerical abnormalities. 2) Frequent structural abnormalities were translocation involving 14q32 (28\%) or 14q11 (14\%), and deletion of $6 \mathrm{q}(23 \%)$. There was no chromosomal abnormality specific for ATL, but abnormalities were detected in the aggressive acute or lymphoma types of ATL rather than in the nonaggressive chronic or smoldering type (43). In situ hybridization techniques disclosed that integrated sites of provirus of HTLV-I were different in each patient, and the random pattern of Southern blotting analyses of the integrated provirus also did not support the idea that HTLV-I integrated to a specific site and activated cellular (onco) genes (45).

It is easy to imagine that ATL cells elaborate many cytokines, because they have originated from activated $\mathrm{T}$ cells. These cytokines are presumed to play an important role in the pathophysiology of ATL. For example, elaborated parathyroid hormone related protein $(\mathrm{PTHr})$ from ATL cells promotes bone resorption and is the major cause of hypercalcemia in ATL patients (46). IL-1 is well known to have multiple biologic activities, such as the induction of neutrophilia and fever. A high fever without overt infection and absolute neutrophilia are frequently found in ATL patients (47). Neutrophilia and eosinophilia are frequently observed in patients with ATL, and some cytokines produced by ATL cells might be the causative factor.

\section{Diagnosis of ATL}

The diagnostic criteria for HTLV-I associated ATL have been defined as follows.

1) Histologically and/or cytologically proven lymphoid malignancy with $\mathrm{T}$ cell surface antigens.

2) Abnormal T-lymphocytes consistently present in the peripheral blood, except in the lymphoma type. These abnormal T lymphocytes include not only typical ATL cells, the so-called flower cells, but also the small mature T-lymphocytes with incised or lobulated nuclei that are characteristic of the chronic or smoldering type.

3) Serum specimens for all patients with ATL have antiHTLV-I antibodies (48). There is no difference in the pattern of serum antibodies between ATL patients and HTLV-I carriers. The presence of serum antibodies to HTLV-I can be demonstrated by indirect immunofluorescence, enzyme-linked immunosorbance, passive hemagglutination, and by Western blotting methods.

4) Demonstration of clonality of HTLV-I proviral DNA is essential to diagnosis of ATL. Southern blot analysis was used for this purpose $(49,50)$. We developed the novel method using inverse polymerase chain reaction to detect the clonality of HTLV-I proviral DNA (51). Diagnosis could be made within 3 days using this method. It enabled us to detect specifically the presence of minimal numbers of ATL cells with high sensitivity.

There are a few patients with 'ATL not associated with HTLV-I' (52). These patients have a CD4+ T cell malignancy not caused by HTLV-I infection and develop a disease very similar to that of ATL. It is, however, evident that the clinical manifestations and hematological features of ATL are not caused by HTLV-I infection per se but by malignant proliferation of CD4+ peripheral T cells. It is natural that an indistinguishable disease occurs when CD4+ peripheral T cells un- 
dergo malignant transformation by any mechanism(s) other than HTLV-I infection. From our experience, patients with 'ATL not associated with HTLV-I' certainly occur but are rare cases with no geographical predilection. Further investigation is needed.

\section{Treatment of ATL and prevention of HTLV-I infection}

ATL is generally treated with curative intent using combination chemotherapy, although long-term success has been very limited. The acute form, with hypercalcemia, high LDH levels and an elevated white blood cell count carries a particular poor prognosis. Sequential trials in Japan have resulted in the complete remission rate being increased from $16 \%$ with a four drug combination to $43 \%$ with eight drugs (53). Unfortunately that advance did not translate into an improvement in the overall survival; the median remain 8 months, with deaths usually the result of severe respiratory infection or hypercalcemia, often associated with drug resistance. In contrast, smoldering ATL, or some cases of chronic ATL, may have a more protracted natural course, which may be compromised by aggressive chemotherapy. Alternative strategies for both acute and chronic forms are clearly needed.

Regardless of the specific antileukemic therapy, the inevitable impairment of the $T$ cell function puts the patient at high risk of fungal, protozoal, and viral infections, against which prophylactic measures should be taken.

Deoxycoformycin, the nucleotide analog, was reported to induce long-term remission in a patient with ATL in 1985 (54). Subsequently, Yamaguchi et al (55) prolonged CR in 2 out of 7 patients. There was profound lymphopenia, but no neutropenia. Waldmann et al (56) administered anti-Tac monoclonal antibody to 19 patients and achieved remission in 7, including CRs. Further studies are obviously required to show whether either of these approaches will have a major impact on the illness.

Irinotecan, an inhibitor of topoisomerase I, was evaluated in 13 patients with ATL, and one complete remission and four partial remissions were achieved (57). It has recently been reported that the combination of zidovudine and interferon alpha may be an effective treatment for $\operatorname{ATL}(58,59)$. The mechanism of antileukemic activity of this combination is unknown.

Prevention of ATL by reducing transmission of HTLV-I is obviously a more attractive goal. To prevent infection with HTLV-I by blood transfusion, all donated blood at blood centers in Japan were subjected to HTLV-I antibody testing beginning in November 1986. None of the recipients, even patients with hematologic disorders who received multiple transfusions, were seroconverted. Although experiments have disclosed that vaccination in Japan, because of the absolute decline of the carrier rate among the young generation (60), complete achievement of blood donor screening, and success in the prevention of the majority of the maternal transmission by refraining from breast feeding.

\section{HTLV-I related diseases}

HTLV-I infection is a direct cause of ATL. However, infection with this virus has also been found to be an indirect cause of or a contributing factor in many other diseases, such as HTLV-I associated myelopathy/tropical spastic paraparesis (HAM/TSP) $(61,62)$, chronic lung diseases, opportunistic lung infections, cancers of other organs (63), monoclonal gammopathy (64), chronic renal failure (65), strongyloidiasis (66), nonspecific intractable dermatomycosis, HTLV-I associated lymphadenitis (67), and uveitis (68). The association of HTLV-I infection with these diseases is considered to be due, to some extent, to the immunodeficiency induced by HTLV-I infection. Also the high seropositivity of HTLV-I in patients with cancers was reported, suggesting that the impaired immune system by HTLV-I infection might play a role in carcinogenesis.

\section{References}

1) Takatsuki K, Uchiyama T, Sagawa K, Yodoi J. Adult T-cell leukemia in Japan. in: Topics in Hematology, Seno S, Takaku F, Irino S, Eds, Excerpta Medica, Amsterdam, 1977, p.73.

2) Uchiyama $T$, Yodoi J, Sagawa $K$, et al. Adult T-cell leukemia: Clinical and hematologic features of 16 cases. Blood 50: 481, 1977.

3) Poiesz BJ, Ruscetti FW, Gazdar AF, et al. Detection and isolation of type $\mathrm{C}$ retrovirus particles from fresh and cultured lymphocytes of a patient with cutaneous T-cell lymphoma. Proc Natl Acad Sci USA 77: 7415, 1980.

4) Miyoshi I, Kubonishi I, Sumida M, et al. A novel T-cell line derived from adult T-cell leukemia. Gann 71: 155, 1980.

5) Hinuma T, Nagata K, Hanaoka M, et al. Adult T-cell leukemia: Antigen in an ATL cell line and detection of antibodies to the antigen in human sera. Proc Natl Acad Sci USA 78: 6476, 1981.

6) Yoshida M, Miyoshi I, Hinuma Y. Isolation and characterization of retrovirus from cell lines of human adult $\mathrm{T}$-cell leukemia and its implication in the disease. Proc Natl Acad Sci USA 79: 2031, 1982.

7) Seiki M, Hattori S, Hirayama Y, Yoshida M. Human adult T-cell leukemia virus: complete nucleotide sequence of the provirus genome integrated in leukemic cells DNA. Proc Natl Acad Sci USA 80: 3618 , 1983.

8) Seiki M, Hattori S, Yoshida M. Human adult T-cell leukemia virus: molecular cloning of the provirus DNA and the unique terminal structure. Proc Natl Acad Sci USA 79: 6899, 1982.

9) Fujisawa J, Seiki M, Sato M, Yoshida M. A transcriptional enhancer sequence of HTLV-I is responsible for trans-activation mediated by $\mathrm{p} 40^{\times}$ of HTLV-I. EMBO J 5: 713, 1986.

10) Inoue J-I, Seiki M, Taniguchi $T$, et al. Induction of interleukin 2 receptor gene expression by $40^{\mathrm{x}}$ encoded by human $\mathrm{T}$-cell leukemia virus type 1 . EMBO J 5: 2883, 1986.

11) Sodroski J, Rosen C, Goh WC, Haseltine W. A transcriptional activator protein encoded by the $\mathrm{x}$-lor region of the human T-cell leukemia virus. Science 228: 1430, 1985.

12) Tajima K, Tominaga S, Kuroishi $T$, et al. Geographical features and epidemiological approach to endemic T-cell leukemia/lymphoma in Japan. Jpn J Clin Oncol 9: 495, 1979.

13) Blattner WA, Kalyanaraman VS, Robert-Guroff, et al. The human type$\mathrm{C}$ retrovirus, HTLV, in Blacks from the Caribbean region, and relationship to adult T-cell leukemia/lymphoma. Int J Cancer 30: 257, 1982.

14) Catovsky D, Greaves MF, Rose M, et al. Adult T-cell lymphomaleukaemia in blacks from the West Indies. Lancet 1: 639, 1982.

15) Fleming AF, Yamamoto N, Bhusnurmath SR, et al. Antibodies to ATLV (HTLV) in Nigerian blood donors and patients with chronic lymphatic leukaemia or lymphoma. Lancet 2: 334, 1983. 
16) Kazura JW, Saxinger WC, Wenger J, et al. Epidemiology of human T cell leukemia virus type I infection in East Sepik province, Papua New Guinea. J Infect Dis 155: 1100, 1987.

17) Yanagihara $R$, Ajdukiewicz $A B$, Garruto RM, et al. Human T-lymphotropic virus type I infection in the Solomon Islands. Am J Trop Med Hyg 44: 122, 1991.

18) Maeda $Y$, Fukuhara $M$, Takehara $Y$, et al. Prevalence of possible adult $T$ cell leukemia virus carriers among volunteer blood donors in Japan: a nation-wide study. Int J Cancer 33: 717, 1984.

19) Tajima K, Hinuma Y.Epidemiology of HTLV-I/II in Japan and the world. in: Advances in Adult T-cell Leukemia and HTLV-I Research. Gann Monograph on Cancer Research, Takatsuki K, Hinuma Y, Yoshida M, Eds. Japan Scientific Societies Press, Tokyo, 39, 1992, p.129.

20) Yamaguchi $K$, Nishimura $H$, Seiki $M$, et al. Clinical diversity in adult $T$ cell leukemia-antibodies to adult T-cell leukemia virus-associated antigen (ATLA) in sera from patients with ATL and controls. Rec Adv RES Res 23: 179, 1983.

21) Kinoshita K, Hino S, Amagasaki $T$, et al. Demonstration of adult T-cell leukemia virus antigen in milk from three sero-positive mothers. Gann 75: 103, 1984

22) Hino S. Maternal-infant transmission of HTLV-I: implication for disease. in: Human Retrovirology: HTLV, Blattner WA, Ed. Raven Press, New York, 1990, p.363.

23) Miyamoto $Y$, Yamaguchi $\mathrm{K}$, Nishimura $\mathrm{H}$, et al. Familial adult $\mathrm{T}$-cell leukemia. Cancer 55: 181, 1985.

24) Okochi K, Sato H, Hinuma $Y$. A retrospective study on transmission of adult T-cell leukemia virus by blood transfusion: seroconversion in recipients. Vox Sang 46: 245, 1984.

25) Kiyokawa $T$, Yamaguchi K, Takeya M, et al. Hypercalcemia and osteoclast proliferation in adult T-cell leukemia. Cancer 59: 1187, 1987.

26) Vukelja SJ, Weiss RB, Perry DJ, et al. Eosinophilia associated with adult T cell leukemia/lymphoma. Cancer 62: 1527, 1988.

27) Tsuda H, Sawada T, Sakata K-M, Takatsuki K. Possible mechanisms for the elevation of serum b2-microglobulin levels in adult T-cell leukemia. Int J Hematol 55: 179, 1992.

28) Yamaguchi K, Nishimura $Y$, Kiyokawa $T$, et al. Elevated serum levels of soluble interleukin-2 receptors in HTLV-I-associated myelopathy. J Lab Clin Med 114: 407, 1989.

29) Yasuda N, Lai PK, Ip SH, et al. Soluble interleukin 2 receptors in sera of Japanese patients with adult T-cell leukemia mark activity of disease. Blood 71: 1021, 1988.

30) Yamaguchi K, Lee SY, Shimizu T, et al. Concurrence of lymphoma type adult T-cell leukemia in three sisters. Cancer 56: 1688, 1985.

31) Kawano F, Yamaguchi K, Nishimura H, et al. Variation in the clinical courses of adult $\mathrm{T}$-cell leukemia. Cancer 55: 851, 1985.

32) Shimoyama M, and members of The Lymphoma Study Group (19841987). Diagnostic criteria and classification of clinical subtypes of adult T-cell leukemia-lymphoma. Br J Haematol 79: 428, 1991.

33) Yoshioka R, Yamaguchi K, Yoshinaga T, Takatsuki K. Pulmonary complications in patients with adult T-cell leukemia. Cancer 55: 2491, 1985.

34) Yamaguchi K, Matutes E, Catovsky D, et al. Strongyloides stercoralis as candidate co-factor for HTLV-I-induced leukaemogenesis. Lancet 2: 94 , 1987.

35) Gibbs WN, Lofters WS, Campbell M, et al. Adult T-cell leukemia/ lymphoma in Jamaica and its relationship to human T-cell leukemia/ lymphoma virus type I-associated lymphoproliferative disease. in: Miwa M, et al. Eds. Retroviruses in Human Lymphoma/Leukemia. Japan Scientific Societies Press, Tokyo, 1985, p.77.

36) Hattori $T$, Uchiyama $T$, Toibana $T$, et al. Surface phenotype of Japanese adult $\mathrm{T}$-cell leukemia cells characterized by monoclonal antibodies. Blood 58: 645, 1981.

37) Matsuoka M, Hattori $T$, Chosa $T$, et al. $T 3$ surface molecules on adult $T$ cell leukemia cells are modulated in vivo. Blood 67: 1070, 1986.

38) Greene WC, Leonard WJ, Wano Y, et al. Trans-activator gene of HTLVII induces IL-2 receptor and IL-2 cellular gene expression. Science 232: 877-880, 1986.
39) Seiki M, Hikikoshi A, Taniguchi T, Yoshida M. Expression of the $\mathrm{pX}$ gene of the HTLV-I: general splicing mechanism in the HTLV family. Science 228: 1532, 1985.

40) Yodoi J, Uchiyama T. IL-2 receptor dysfunction and adult T-cell leukemia. Immunol Rev 92: 135, 1986.

41) Arina N, Daitoku Y, Ohgaki S, et al. Autocrine growth of interleukin 2producing leukemic cells in a patient with adult $\mathrm{T}$ cell leukemia. Blood 68: 779, 1986.

42) Ueshima $Y$, Fukuhara $S$, Hattori $T$, et al. Chromosome studies in adult $T$ cell leukemia in Japan. Significance of trisomy 7. Blood 58: 420, 1981.

43) Sanada I, Tanaka R, Kumagai E, et al. Chromosomal aberrations in adult T-cell leukemia relationship to the clinical severity. Blood 65: 649, 1985.

44) Kamada N, Sakurai M, Miyamoto K, et al. Chromosome abnormalities in adult $\mathrm{T}$ cell leukemia/lymphoma: a karyotype review committee report. Cancer Res 52: 1481, 1992.

45) Seiki M, Eddy R, Shows TB, Yoshida M. Nonspecific integration of the HTLV provirus genome into adult T-cell leukemia cells. Nature 309: 640, 1984.

46) Watanabe $T$, Yamaguchi K, Takatsuki K, et al. Constitutive expression of parathyroid hormone-related protein gene in human $\mathrm{T}$ cell leukemia virus type 1 (HTLV-1) carriers and adult T cell leukemia patients that can be trans-activated by HTLV-1 tax gene. J Exp Med 172: 759, 1990.

47) Yamamoto $S$, Hattori $T$, Asou $N$, et al. Absolute neutrophilia in adult $T$ cell leukemia. Jpn J Cancer Res (Gann) 77: 858, 1986.

48) Schneider J, Yamamoto N, Hinuma Y, Hunsmann G. Sera from adult T cell leukemia virus. Virology 132: 1, 1984.

49) Yoshida M, Seiki M, Yamaguchi K, Takatsuki K. Monoclonal integration of human T-cell leukemia provirus in all primary tumors of adult T-cell leukemia suggests causative role of human T-cell leukemia virus in disease. Proc Natl Acad Sci USA 81: 2534, 1984.

50) Yamaguchi K, Seiki M, Yoshida M, et al. The detection of human T cell leukemia virus proviral DNA and its application for classification and diagnosis of T-cell malignancy. Blood 63: 1235, 1984.

51) Takemoto $S$, Matsuoka M, Yamaguchi K, Takatsuki K. A novel diagnostic method of adult T-cell leukemia: Monoclonal integration of human Tcell lymphotropic virus type I provirus DNA detected by inverse polymerase chain reaction. Blood 84: 3080, 1994.

52) Shimoyama M, Kagami Y, Shimotohno K, et al. Adult T-cell leukemia/ lymphoma not associated with human T-cell leukemia virus type I. Proc Natl Acad Sci USA 83: 4524, 1986.

53) Minato K, Araki K, Hanada S, et al. An interim report of LSG4 treatment for advanced peripheral T-cell lymphoma. Int J Hematol 54: 179, 1991.

54) Daenen S, Rojer RA, Smit JW, et al. Successful chemotherapy with deoxycoformycin in adult T-celi lymphoma-leukaemia. Br J Haematol 58: 723, 1984

55) Yamaguchi K, Lee SY, Oda T, et al. Clinical consequences of 2'deoxycorfomycin treatment in patients with refractory adult T-cell leukemia. Leukemia Res 10: 989, 1986.

56) Waldmann TA, White JD, Goldman CK, et al. The interleukin-2 receptor: a target for monoclonal antibody treatment of human T-cell lymphotrophic virus I-induced adult-T cell leukemia. Blood 82: 1701, 1993.

57) Tsuda $\mathrm{H}$, Takatsuki K, Ohno R, et al. Treatment of adult T-cell leukemialymphoma with irinotecan hydrochloride (CPT-11). Br J Cancer 70: 771, 1994.

58) Gill PS, Harrington W Jr, Kaplan MH, et al. Treatment of adult T-cell leukemia-lymphoma with a combination of interferon alfa and zidovudine. N Engl J Med 332: 1744, 1995.

59) Hermine O, Bouscary D, Gessain A, et al. Treatment of adult T-cell leukemia-lymphoma with zidovudine and interferon alfa. N Engl J Med 332: 1749, 1995.

60) Oguma S, Imamura $Y$, Kusumoto $Y$, et al. Accelerated declining tendency of human $\mathrm{T}$-cell leukemia virus type I carrier rates among younger blood donors in Kumamoto, Japan. Cancer Res 52: 2620, 1992.

61) Gessain A, Barin F, Vernant JC, etal. Antibodies to human T-lymphotropic virus type I in patients with tropical spastic paraparesis. Lancet 2: 407, 1985.

62) Osame M, Usuku K, Izumo S, et al. HTLV-I associated myelopathy, a 


\section{TAKATSUKI}

new clinical entity. Lancet 1: 1031, 1986.

63) Asou N, Kumagai T, Uekihara S, et al. HTLV-I seroprevalence in patients with malignancy. Cancer 58: 903, 1986.

64) Matsuzaki H, Yamaguchi K, Kagimoto T, et al. Monoclonal gammopathies in adult T-cell leukemia. Cancer 56: 1380, 1985.

65) Lee SY, Matsushita K, Machida J, et al. Human T-cell leukemia virus type I infection in hemodialysis patients. Cancer 60: 1474, 1987.

66) Nakada K, Yamaguchi K, Furugen S, et al. Monoclonal integration of
HTLV-I proviral DNA in patients with strongyloidiasis. Int J Cancer 40: 145, 1987.

67) Yamaguchi K, Yoshioka R, Kiyokawa T, et al. Lymphoma type adult Tcell leukemia - a clinicopathologic study of HTLV related T-cell type malignant lymphoma. Hematol Oncol 4: 59, 1986.

68) Mochizuki M, Watanabe T, Yamaguchi K, et al. HTLV-I uveitis: a distinct clinical entity caused by HTLV-I. Jpn J Cancer Res 83: 236, 1992. 